\title{
Dual roles of the transmembrane protein P23/TMP2I in the modulation of amyloid precursor protein metabolism
} Kulandaivelu S Vetrivel ${ }^{\dagger 1}$, Ping Gong ${ }^{\dagger 1}$, James W Bowen ${ }^{\dagger 2}$, Haipeng Cheng ${ }^{1}$, Ying Chen ${ }^{1}$, Meghan Carter ${ }^{1}$, Phuong D Nguyen ${ }^{3}$, Lisa Placanica ${ }^{4}$, Felix T Wieland ${ }^{5}$, Yue-Ming Li $^{4}$, Maria Z Kounnas ${ }^{3}$ and Gopal Thinakaran*1,2

Address: ${ }^{1}$ Departments of Neurobiology and Neurology, The University of Chicago, Chicago, IL 60637, USA, ${ }^{2}$ Committee on Neurobiology, The University of Chicago, Chicago, IL 60637, USA, ${ }^{3}$ TorreyPines Therapeutics, Inc. La Jolla, CA 92037, USA, ${ }^{4}$ Molecular Pharmacology and Chemistry Program, Memorial Sloan-Kettering Cancer Center, New York, NY 10021, USA and ${ }^{5}$ Biochemie-Zentrum der Universitat Heidelberg, Im Neuenheimer Feld 328, D-69120 Heidelberg, Germany

Email: Kulandaivelu S Vetrivel - vetrivel@uchicago.edu; Ping Gong - gong_ping@hotmail.com; James W Bowen - Jim_bowen1000@yahoo.com; Haipeng Cheng - hcheng@bsd.uchicago.edu; Ying Chen - ying1@uchicago.edu; Meghan Carter - mcarter@bsd.uchicago.edu; Phuong D Nguyen - pnguyen@torreypinestherapeutics.com; Lisa Placanica - placanil@mskcc.org; Felix T Wieland - felix.wieland@bzh.uniheidelberg.de; Yue-Ming Li - liy2@mskcc.org; Maria Z Kounnas - mkounnas@torreypinestherapeutics.com; Gopal Thinakaran* -gopal@uchicago.edu

* Corresponding author †Equal contributors

Published: 8 February 2007

Molecular Neurodegeneration 2007, 2:4 doi:10.1/86/1750-1326-2-4
Received: 29 January 2007

Accepted: 8 February 2007

This article is available from: http://www.molecularneurodegeneration.com/content/2/1/4

(c) 2007 Vetrivel et al; licensee BioMed Central Ltd.

This is an Open Access article distributed under the terms of the Creative Commons Attribution License (http://creativecommons.org/licenses/by/2.0), which permits unrestricted use, distribution, and reproduction in any medium, provided the original work is properly cited.

\begin{abstract}
Background: Alzheimer's disease (AD) is characterized by cerebral deposition of $\beta$-amyloid (A $\beta$ ) peptides. $A \beta$ is released from ectodomain cleaved amyloid precursor protein (APP) via intramembranous proteolysis by $\gamma$-secretase, a complex consisting of presenilin and a few other proteins. P23/TMP2I, a member of the p24 family type I transmembrane proteins, was recently identified as a presenilin complex component capable of modulating $\gamma$-secretase cleavage. The p 24 family proteins form oligomeric complexes and regulate vesicular trafficking in the early secretory pathway, but their role in APP trafficking has not been investigated.

Results: Here, we report that siRNA-mediated depletion of p23 in N2a neuroblastoma and HeLa cells produces concomitant knockdown of additional p24 family proteins and increases secretion of sAPP. Furthermore, intact cell and cell-free $A \beta$ production increases following p23 knockdown, similar to data reported earlier using HEK293 cells. However, we find that p23 is not present in mature $\gamma$-secretase complexes isolated using an active-site $\gamma$-secretase inhibitor. Depletion of p23 and expression of a familial AD-linked PSI mutant have additive effects on $A \beta_{42}$ production. Knockdown of p23 expression confers biosynthetic stability to nascent APP, allowing its efficient maturation and surface accumulation. Moreover, immunoisolation analyses show decrease in coresidence of APP and the APP adaptor Mint3. Thus, multiple lines of evidence indicate that p23 function influences APP trafficking and sAPP release independent of its reported role in $\gamma$-secretase modulation.
\end{abstract}

Conclusion: These data assign significance to P24 family proteins in regulating APP trafficking in the continuum of bidirectional transport between the ER and Golgi, and ascribe new relevance to the regulation of early trafficking in $A D$ pathogenesis. 


\section{Background}

Amyloid precursor protein (APP) is a type I membrane protein that is trafficked through the secretory and endocytic pathways in neuronal and non-neuronal cells, and is the precursor to $40-42$ amino acid residue $\beta$-amyloid peptides $(A \beta)$. Cerebral deposition of $A \beta$ in senile plaques is a pathological feature of patients with Alzheimer's disease (AD), and $A \beta$ deposits are also found in aged individuals. $A \beta$ is liberated from APP via sequential proteolysis by $\beta$ - and $\gamma$-secretases [1]. Cleavage of APP within the lumenal domain by BACE1, the major neuronal $\beta$-secretase, releases the APP ectodomain and generates the $\mathrm{N}$-terminus of $\mathrm{A} \beta$ [2]. The APP ectodomain can also be released by cleavage at the " $\alpha$-secretase" site within the $A \beta$ domain by zinc metallopreotases such as TACE/ADAM17, ADAM9, ADAM10 and MDC-9, and an aspartyl protease BACE2 [3]. The C-terminal APP stubs (APP CTFs) resulting from $\alpha$ - and $\beta$-secretase cleavage serve as substrates for intramembranous proteolysis by $\gamma$-secretase, a multimeric complex made of presenilin (PS) 1 or 2, nicastrin, APH1 and PEN2 [4]. Mature components of the $\gamma$-secretase complex are found, and shown to be enzymatically active, at the cell surface as well as in multiple organelles such as the ER/Golgi intermediate compartment (ERGIC), Golgi apparatus, trans-Golgi network (TGN), and late endosomes [5]. Activation of Notch signaling also involves sequential proteolytic processing, which closely resembles proteolysis of APP. Following ligand binding at the cell surface, Notch is endocytosed and sequentially cleaved by ADAM family metalloproteases and $\gamma$-secretase [6]. Enhancer/suppressor screen studies in Caenorhabditis elegans originally suggested a role for $\mathrm{p} 24$ proteins in the transport regulation of Notch receptors to the cell surface [7]. Reducing the activity of the p24 family member SEL9 increased the cell surface accumulation of a transportdefective GLP-1 mutant, and increased the activity of mutant LIN-12 or GLP-1. Recently $\gamma$-secretase complex was found to contain p23 (also called TMP21), a p24 family protein. Intriguingly, reducing p23 expression resulted in increased $\gamma$-secretase cleavage of APP, without affecting the proteolysis of Notch [8].

The p24 proteins are a phylogenetically-conserved family of type I transmembrane proteins [9] that are highly enriched in the ER, Golgi, and coat protein (COP) I and II transport vesicles $[10,11]$. Mammalian p24 family consists of six members, p23/TMP21, p24/p24a, p25/gp25L, p26/p24b, p27, and tp24, which function as hetero-oligomeric complexes [12]. Sorting motifs in the cytosolic tail of p24 proteins bind to coat proteins of COPI and COPII vesicles [13-16], and ADP-ribosylation factor 1 (ARF1) [17]. Furthermore, p23, p24a, and p25 are present in complexes with the Golgi reassembly stacking proteins GRASP55 and GRASP65 [18]. A yeast strain lacking all eight members of the p24 family was viable displaying only minor secretory deficits [19], while in mice targeted disruption of both p23 alleles resulted in early embryonic lethality [20]. Proposed roles of the p24 proteins include COP vesicle cargo receptors, regulators of COP vesicle budding, ER quality control, and organization of the Golgi apparatus [7,13,16,21-25]. Recent evidence suggests that p24 proteins may specifically populate a subset of COPI vesicles [26] or influence the formation of tubular transport intermediates [27]. Thus, their precise role in early secretory pathway trafficking, and more importantly sorting of specific cargo, still remains elusive.

Here, we investigated p23 modulation of APP metabolism and report that diminution of p23 expression in non-neuronal and neuroblastoma cell lines leads to increased biosynthetic stability and maturation of nascent APP, cell surface accumulation of APP, as well as secretion of sAPP. Selective increase in $A \beta_{42}$ production associated with a familial AD (FAD)-linked PS mutation occurs independently of p23 modulation of APP metabolism. Finally, immunoisolation and immunofluorescence analysis reveals redistribution of APP and its adaptor Mint $3 / \mathrm{X} 11 \gamma$ in cells with knockdown of p23 expression, suggesting a potential mechanism by which p23 may influence APP trafficking and sAPP release. Our data reveal a novel role for the p24 family proteins in regulating early secretory pathway trafficking of holo APP in addition to the recently reported modulation of $\gamma$-secretase cleavage of APP CTFs.

\section{Results siRNA knockdown of $p 23$ expression affects secretion of APPs and $A \beta$ peptides in mouse neuroblastoma cells}

Transfection with synthetic p23 siRNA markedly attenuated p23 expression ( $>85 \%$ knockdown of p23 expression) in mouse N2a neuroblastoma cells relative to nonspecific control siRNA transfection (Fig. 1A). Previously based on deletion analysis in yeast and mammalian cells, it was reported that members of the p24 family depend on each other for proper assembly into stable oligomeric complexes $[20,28]$. Consistent with this prediction and a recent report [8], p23 knockdown produced concomitant reduction in the levels of p24, p25, and tp24. The steadystate levels of the ER resident transmembrane protein calnexin, Golgi associated $\beta$-COP subunit of the coatomer, and Golgi matrix proteins p115 and Grasp55 were unaffected by p23 knockdown (Fig. 1). However, we noted minor increase in PS1 NTF as well as an increase in the levels of immature and mature nicastrin, but the levels of PEN2 remained unchanged. In accordance with the recent report by Chen et al. [8], siRNA knockdown of p23 expression in N2a cells stably expressing an FAD-linked APP mutant (N2aSwe cells) increased secretion of $\mathrm{A} \beta_{40}$ by $55 \%$ $(10.7 \mathrm{ng} / \mathrm{ml}$ in NS siRNA cells versus $16.7 \mathrm{ng} / \mathrm{ml}$ in $\mathrm{p} 23$ siRNA cells; $p<0.05)$ and $A \beta_{42}$ by approximately 4.5 -fold $(0.08 \mathrm{ng} / \mathrm{ml}$ in NS siRNA cells versus $0.38 \mathrm{ng} / \mathrm{ml}$ in $\mathrm{p} 23$ 

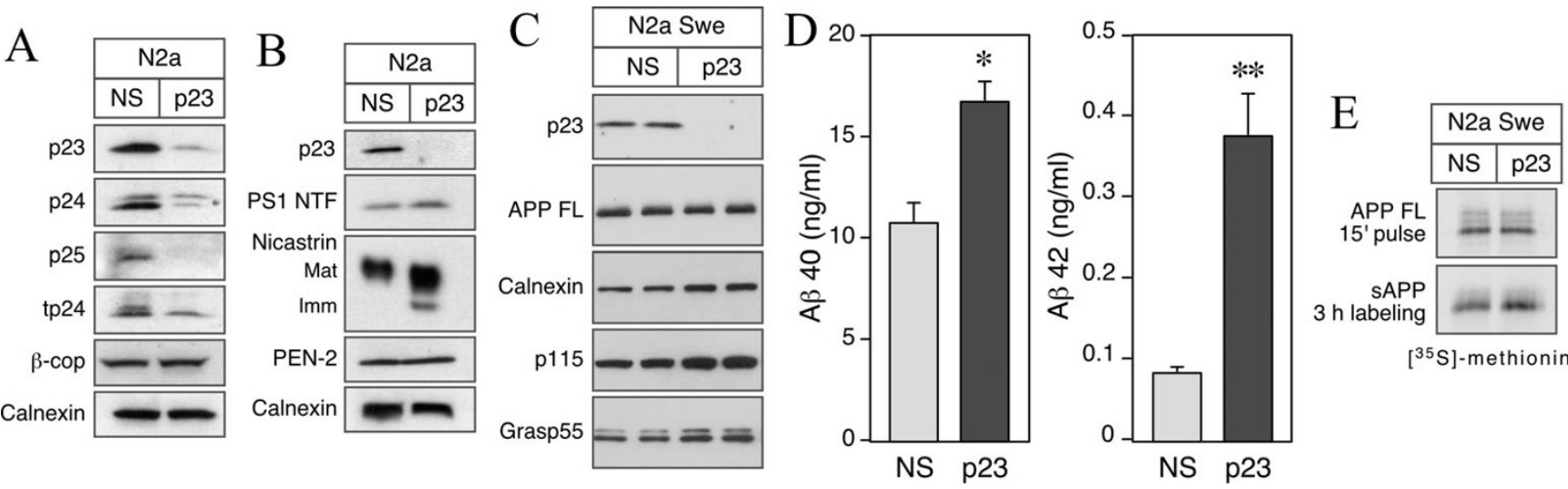

$\left[{ }^{35} \mathrm{~S}\right]$-methionine

Figure I

siRNA-mediated depletion of p23 in N2a cells affects APP metabolism. A and B, Lysates of N2a cells transfected with control non-specific (NS) or p23 siRNA were probed with antibodies specific for four p24 family members, three components of the $\gamma$-secretase, $\beta$-COP, and calnexin. Knockdown of p23 expression causes co-ordinate diminution the steady-state levels of p24, p25 and tp24. Also note the increased accumulation of immature and mature nicastrin in p23-depleted cells. C, Lysates of siRNA transfected N2aSwe cells were probed with antibodies specific for APP, calnexin, pI I5, and Grasp55. D, Secreted $A \beta_{40}$ and $A \beta_{42}$ in the media conditioned by $N 2 a$ Swe were quantified using two-site ELISAs. The data represent mean \pm SEM of three sets of transfections. $* p<0.05$; ${ }^{* *} p<0.01$. E, N2aSwe cells were labeled with $\left.{ }^{35} \mathrm{~S}\right] \mathrm{met} / \mathrm{cys}$ for $15 \mathrm{~min}$ and APP FL were immunoprecipitated from cell lysates using Ab 369 (top); sAPP were immunoprecipitated using mAb P2-I from media of cells labeled for $3 \mathrm{~h}$ (bottom).

siRNA cells; $p<0.01)$ as determined by ELISA of conditioned media (Fig. 1D). Thus both the total amount of fibrillogenic $A \beta_{42}$ and the fraction of $A \beta_{42}$ as a percent of total $A \beta$ increased by siRNA depletion of $\mathrm{p} 23$ expression. Next we sought to determine whether secretion of sAPP also parallels increased secretion of $A \beta$ in p23-depleted cells. For this analysis, we immunoprecipitated sAPP from the conditioned media of cells labeled for $3 \mathrm{~h}$ with [ $\left.{ }^{35} \mathrm{~S}\right] \mathrm{met} / \mathrm{cys}$ and normalized sAPP levels to APP synthesis determined by 15 min pulse labeling. By phosphorimager quantification, we observed a 2 -fold increase in the levels of sAPP secreted by N2aSwe cells transfected with p23
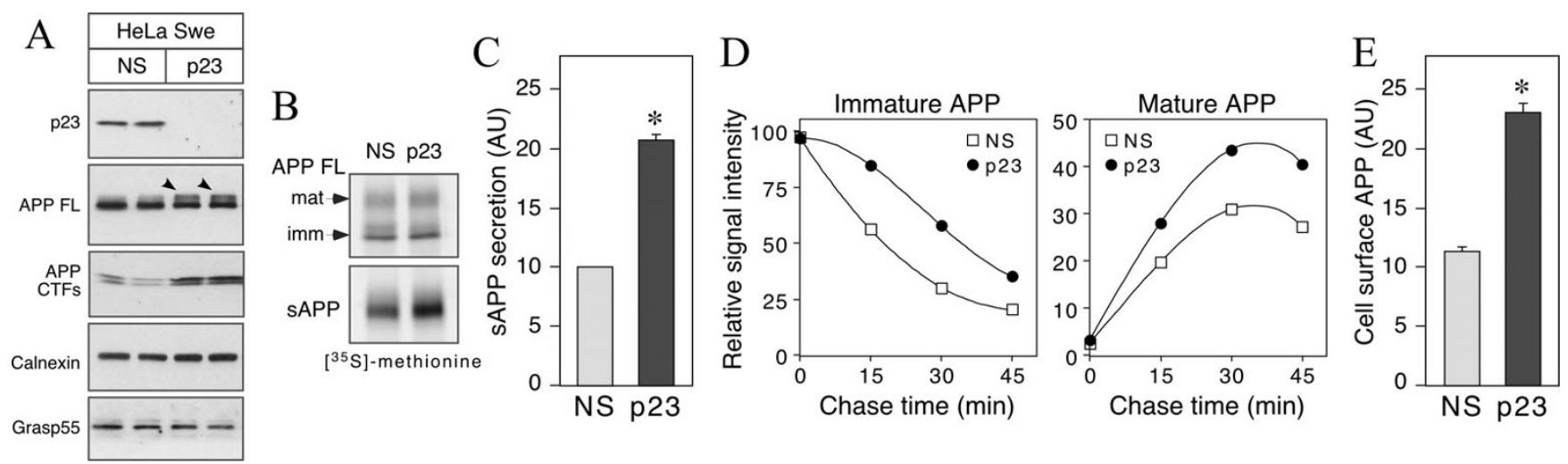

Figure 2

p23 depletion affects APP maturation and secretion in HeLa cells. A, Lysates of HeLa cells transfected with siRNA were probed with antibodies specific for p23, APP, calnexin, and Grasp55. Arrowheads indicate mature glycosylated APP. B, HeLaSwe cells were labeled with [ $\left.{ }^{35} \mathrm{~S}\right] \mathrm{met} / \mathrm{cys}$ for $3 \mathrm{~h}$ and APP FL and sAPP were immunoprecipitated from cell lysates and conditioned media, respectively. C, The levels of SAPP in $3 \mathrm{~h}$-labeled conditioned media were quantified and normalized to APP synthesis determined by $I 5$ min pulse labeling. $A U$, arbitrary units. $D$, HeLaSwe cells were pulse-labeled for $I 5$ min and chased for the times indicated. APP FL was immunoprecipitated from cell lysates and signal intensities of immature and mature APP at each time point were quantified by phosphorimaging and normalized to APP synthesis. $E$, The levels of cell surface APP were quantified by mAb P2-I binding of live cells as descried under Methods. The graphs in $C$ and $E$ represent mean \pm SEM of three sets of transfections $(p<0.00 \mathrm{I})$, and $D$ represents the mean of two experiments. 

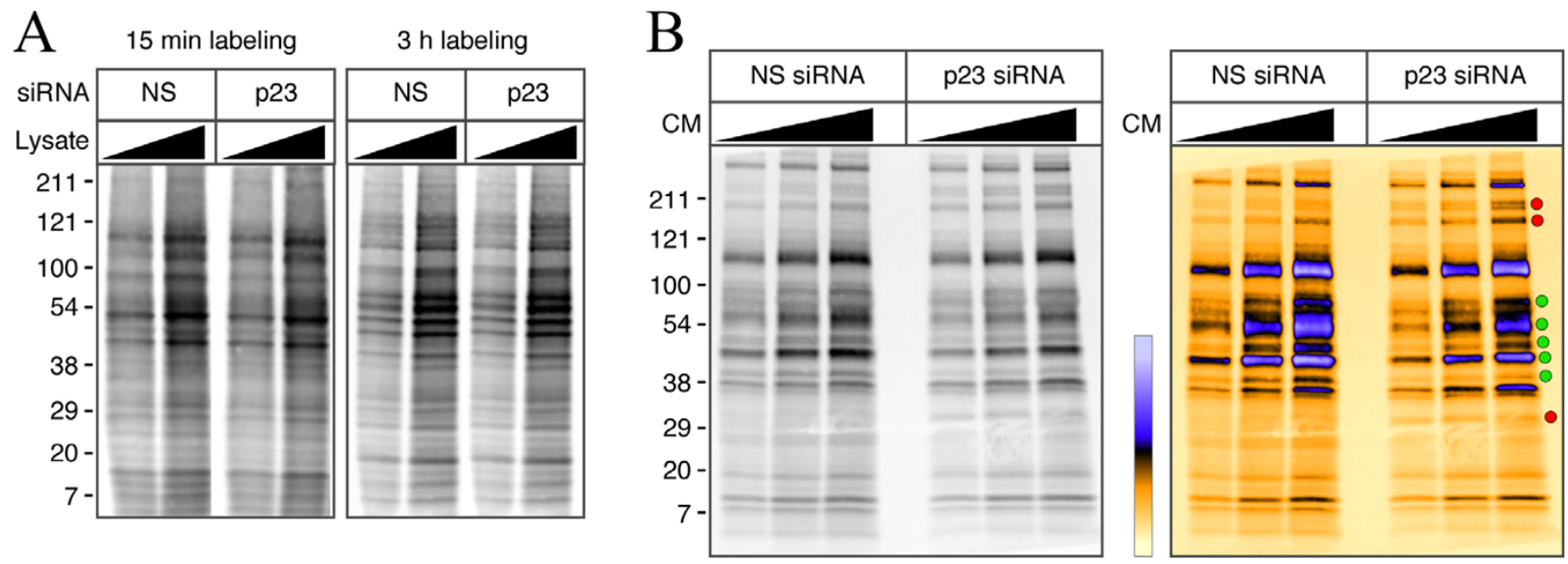

Figure 3

p23 depletion has minor effects on overall protein secretion. $A$, N2aSwe cells transfected with siRNA were labeled with [ $\left.{ }^{35} \mathrm{~S}\right] \mathrm{met} / \mathrm{cys}$ for $15 \mathrm{~min}$ or $3 \mathrm{~h}$. Aliquots of lysates (5 and $\left.10 \mu \mathrm{l}\right)$ were separated by SDS-PAGE and analyzed by phosphorimaging. $B, 5,10$ and $20 \mu \mathrm{l}$ of aliquots of conditioned media (CM) from cells labeled for $3 \mathrm{~h}$ were analyzed. In the panel on the right, the gray scale image is depicted in pseudocolor. Red and green circles indicate increase and decrease in the intensity of secreted polypeptides, respectively, in cells transfected with p23 siRNA relative to NS siRNA.

siRNA (Fig 1E). Our results are in accordance with the earlier reported role for $\mathrm{p} 23$ in modulating $\mathrm{A} \beta$ production, but since p23 knockdown invariably attenuates the expression of several p24 family proteins, our results also suggest a broader role for p24 family proteins in regulating APP metabolism and secretion.

\section{Knockdown of p23 affects APP maturation and cell surface expression}

Compared with the results from HEK293 cells [8], an increase in SAPP release observed in N2a neuroblastoma cells was unexpected. Furthermore, modulation of $\gamma$-secretase activity by p23 interaction with the presenilin complex seems insufficient to explain this perplexing observation on sAPP release, which is dependent on cleavage by $\alpha$ - or $\beta$-secretase. This prompted us to further examine p23 modulation of sAPP secretion in HeLa cells, as an additional non-neuronal cell line. Similar to N2a cells, transient siRNA knockdown of p23 expression in HeLa cells stably expressing an FAD-linked APP mutant (HeLaSwe) also markedly reduced the levels of other p24 family proteins without discernable effects on the levels of PS1, nicastrin, PEN2, $\beta$-COP or calnexin (Fig. 2A and data not shown). However, in p23-depleted cells we noted a clear increase in mature APP (upper band of the doublet), and APP CTFs resulting from cleavage of APP by $\alpha-$ or $\beta$ secretases. Continuous 3 h labeling using [ $\left.{ }^{35} \mathrm{~S}\right] \mathrm{met} / \mathrm{cys}$ followed by immunoprecipitation analysis revealed a 2 -fold increase $(p<0.001)$ in the levels of sAPP released into the media conditioned by p23-depleted cells, despite similar steady-state levels of immature and mature APP holopro- tein relative to non-specific siRNA transfected cells (Fig. $2 \mathrm{~B}$ and $2 \mathrm{C}$ ).

Does p23 knockdown alter the kinetics of nascent APP polypeptide maturation? To address this issue, we performed pulse/chase-labeling experiments. Although APP synthesis is similar to control cells following $15 \mathrm{~min}$ pulse labeling with [35S]met/cys, we found higher levels of immature and mature APP during the chase period in cells transfected with p23 siRNA (Fig. 2D). These data suggest that nascent core-glycosylated APP polypeptides are relatively more stable, and readily undergo complex glycosylation in cells with attenuated expression of p24 proteins. Increased maturation of APP as well as sAPP secretion, suggested the possibility that loss of p23 expression might enhance APP trafficking to the cell surface. Indeed, quantitative analysis revealed a 2-fold increase ( $p$ $<0.001$ ) in the steady-state levels of cell surface APP in cells transfected with p23 siRNA (Fig. 2E). Next, we considered the possibility that p23 depletion and diminution of additional p24 family proteins might cause a general increase in cellular secretion. To test this idea, we assessed total protein synthesis and secretion in p23 depleted cells. SDS-PAGE analysis of detergent lysates prepared from control and p23 siRNA transfected cells showed similar levels of total protein synthesis following $15 \mathrm{~min}$ pulse labeling or $3 \mathrm{~h}$ continuous labeling with [35S]met/cys (Fig. 3A). However, SDS-PAGE analysis of conditioned medium showed decrease in the levels of several secreted polypeptides and small increase in a few polypeptides (Fig. 3B). Thus, depletion of p24 family members does 

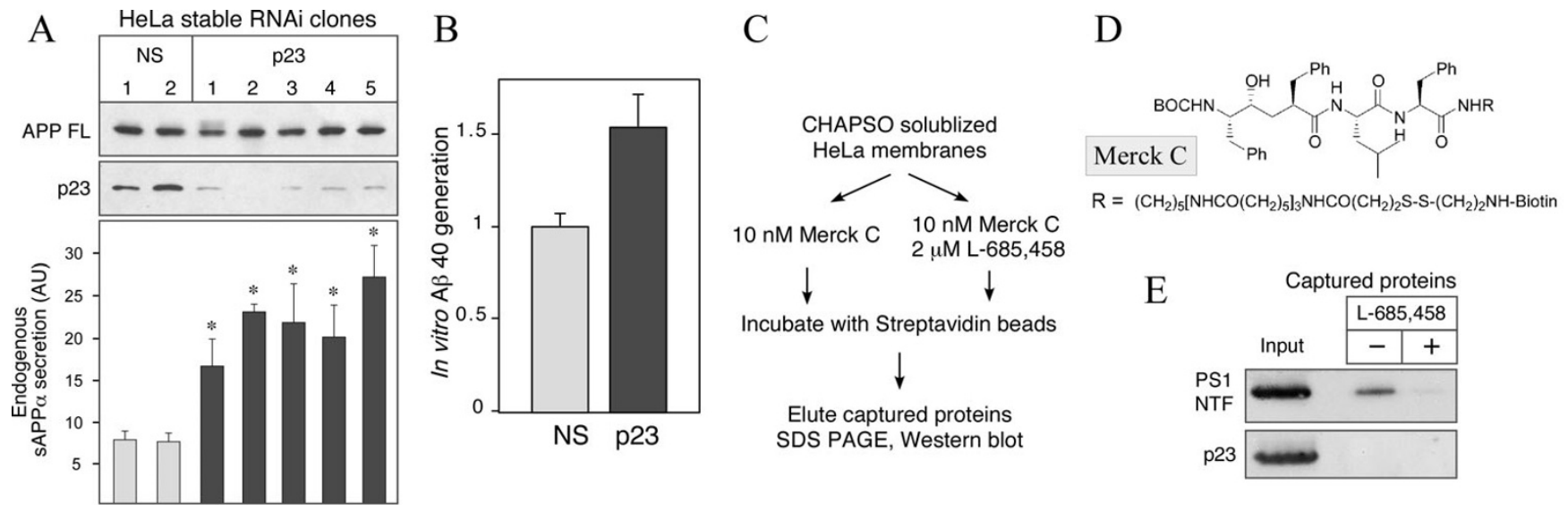

\section{Figure 4}

p23 knockdown APP maturation and secretion in HeLa cells. A, Lysates of HeLa cell lines stably transfected with p23 or control shRNA plasmids were probed with antibodies specific for APP and P23. Quantitative analysis of sAPP $\alpha$ in the media conditioned by each stable cell line was performed using ELISA. The data represent mean \pm SEM of three sets of samples; $p<$ $0.00 \mathrm{I}$. B, Membranes prepared from two control and four P23 knockdown HeLa cell lines were incubated in vitro with Cl00 FLAG substrate and $A \beta_{40}$ generation was quantified by ELISA. C, The strategy for capturing active $\gamma$-secretase using the activesite $\gamma$-secretase inhibitor Merck C. D, The structure of Merck C. E, Solubilized HeLa S3 cell membranes were incubated with biotinylated $\gamma$-secretase inhibitor Merck $C$ in the absence or presence of excess L-685,458. Active $\gamma$-secretase complexes were captured using streptavidin beads and analyzed by immunoblotting.

not affect overall protein synthesis, but causes a small decrease in the secretory potential of the cell. On the other hand, the results described above suggest that p23 plays a role in negatively regulating APP maturation and trafficking, in addition to the reported role in $\gamma$-secretase processing.

\section{Stable knockdown of p23 expression in HeLa cells increases endogenous $s$ APP $\alpha$ secretion}

The data described above were obtained from the analysis of N2a or HeLa cells stably overexpressing FAD-linked mutant APPswe. It is known that secretase processing of wild type APP and APPswe are quite different with respect to the subcellular sites of proteolysis. For example, the presence of "Swedish" mutation renders APPswe extremely susceptible to cleavage by $\beta$-secretase in the biosynthetic organelles such as the Golgi and TGN [29]. Furthermore, because p24 family proteins have a wellestablished role in early secretory pathway trafficking of transport vesicles, p23 regulation of overexpressed APPswe could markedly differ relative to endogenous APP. To confirm increased secretion of sAPP from endogenous wild type APP, we generated HeLa cell lines stably transfected with non-specific control or p23 shRNA plasmids. This later RNAi approach was also effective in stably reducing expression of p23 in independent clones (Fig. 4A). By assaying conditioned media we found that each of the p23 knockdown clones displayed a significant increase in the secretion of endogenous sAPP $\alpha$ relative to clones transfected with the non-specific shRNA plasmid, while the steady-state levels of full-length APP (APP FL) remained unchanged by stable attenuation of $\mathrm{p} 23$ expression (Fig. 4A).

To address whether p23 knockdown influences cell-free generation of $A \beta$ in HeLa cell membranes, we incubated C100FLAG substrate with membranes prepared from control and p23 knockdown clones using a well-established in vitro assay [30]. To demonstrate the specificity in these assays, one set of each sample was incubated in parallel with the $\gamma$-secretase inhibitor L-685,458 to inhibit A $\beta$ production. By ELISA analysis, we found that membrane preparations from p23 knockdown clones generated about $50 \%$ more $A \beta_{40}$ relative to membranes from control clones (Fig. 4B). We then asked whether p23 is incorporated into active $\gamma$-secretase complexes. To this end, we used Merck C, a specific biotinylated transition-state $\gamma$ secretase inhibitor that is capable of capturing active $\gamma$ secretase complexes from membrane preparations [31]. Interestingly, we found that the $\gamma$-secretase protein complexes captured from CHAPSO solubilized HeLa cell membranes contained readily detectable levels of PS1 NTF, but not p23 (Fig. 4E). As expected, we also detected PS1 CTF and nicastrin in $\gamma$-secretase complexes isolated using Merck C (data not shown). Moreover, addition of excess transition-state analog inhibitor L-685,458 prevented the capture, confirming selective isolation of active $\gamma$-secretase complexes by Merck C (Fig. 4E). These results indicate that p23 is not present at $1: 1$ stoichiometry with PS1 as a stable component of active $\gamma$-secretase complexes. 

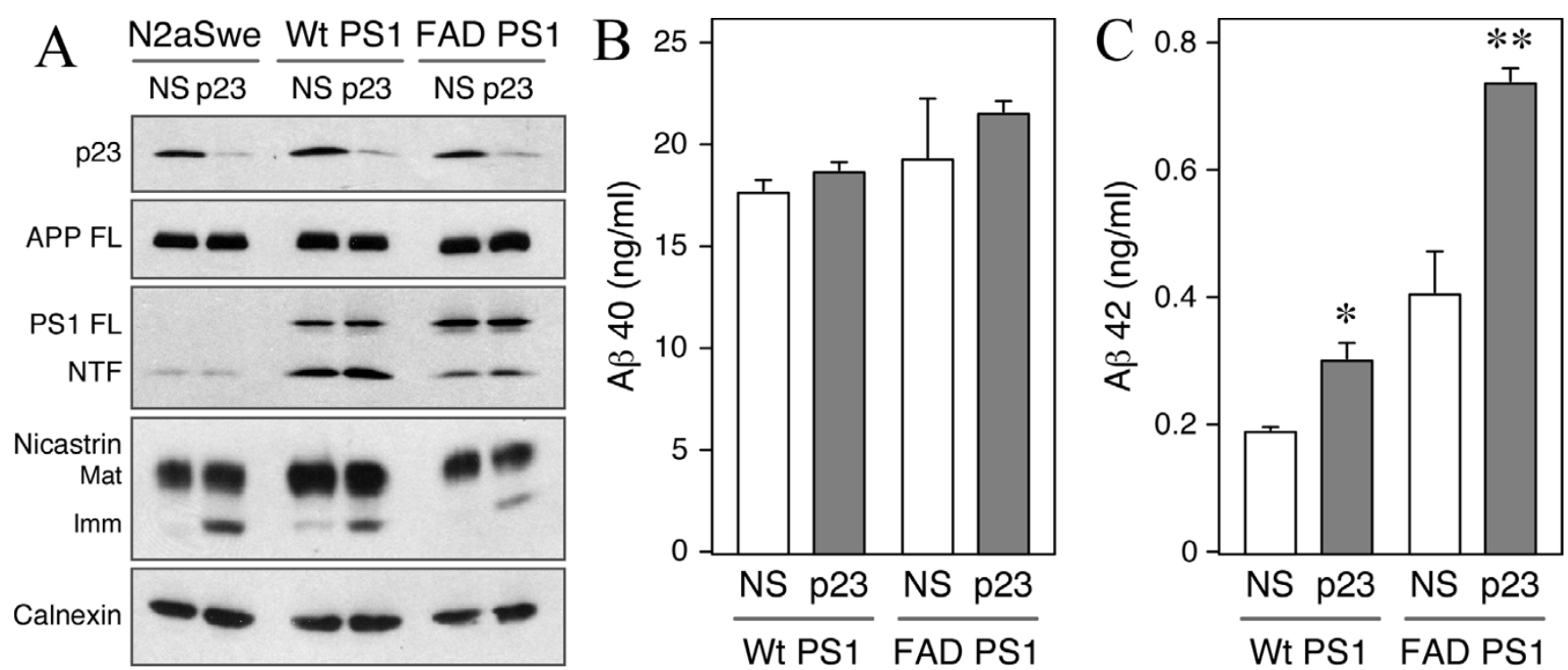

Figure 5

Additive effects of p23 depletion and FAD-linked PSI mutation on APP metabolism. A, Lysates of N2aSwe cells stably expressing wt PSI or C4IOY mutant were probed with antibodies specific for P23, APP, $\gamma$-secretase components, and calnexin. $B$ and $C$, Quantitative analysis of secreted $A \beta_{40}$ and $A \beta_{42}$ in the media conditioned by wt and C4IOY cell lines was performed using two-site ELISAs. The data represent mean \pm SEM of three transfections. $* p<0.05 ; * * p<0.0$ l.

Nevertheless, knockdown of p23 expression can influence in vitro $\mathrm{A} \beta$ production in a cell-free assay using an exogenous APP substrate and membrane preparations from HeLa (our results) or HEK293 cells [8], consistent with modulation of $A \beta$ production by transient interaction of p23 with the mature $\gamma$-secretase complex.

\section{Role of p23 in PSI FAD mutation-associated selective increase of $A \beta_{42}$ secretion}

FAD-linked mutations in PS1 and PS2 selectively elevate the levels of $A \beta_{42}$ peptides by mechanism(s) that is still not clearly understood [32]. In contrast to FAD-linked mutations, knockdown of p23 expression affected multiple aspects of APP metabolism including biosynthetic stabilization of nascent APP and increased secretion of SAPP, $\mathrm{A} \beta_{40}$ and $\mathrm{A} \beta_{42}$ as described above. Therefore, we predicted that p23 modulation of $A \beta_{42}$ production might be indirect, and distinct from the mechanism associated with selective FAD-linked PS1 mutant effect on $A \beta_{42}$ generation. To test this idea, we performed p23 siRNA knockdown studies in N2aSwe derivatives co-expressing APPswe and either wt PS1 or a FAD-linked PS1 variant (C410Y) (Fig. 5A). Knockdown of p23 expression in cells overexpressing either wt or FAD-linked mutant PS1 had no effect on the levels of secreted $A \beta_{40}$ peptides (Fig. 5B). The implication of this finding is not readily apparent, but might be the result of potential interaction between excess holoPS1 present in these cells. Nevertheless, wt PS1 cells transfected with p23 siRNA secreted significantly higher levels of $A \beta_{42}$ relative to cells transfected with non-specific
siRNA $(0.19 \mathrm{ng} / \mathrm{ml}$ in NS siRNA cells versus $0.30 \mathrm{ng} / \mathrm{ml}$ in p23 siRNA cells; $p<0.05$ ) (Fig. 5C). As expected, the C410Y PS1 cells used in these experiments secrete 2-fold higher levels of $\mathrm{A} \beta_{42}$ relative to wt PS1 cells $(0.19 \mathrm{ng} / \mathrm{ml} \mathrm{wt}$ PS1 cells versus $0.41 \mathrm{ng} / \mathrm{ml} \mathrm{C410Y} \mathrm{cells;} p<0.05)$, but secrete comparable levels of $A \beta_{40}$ (Fig. $5 \mathrm{~B}$ and $5 \mathrm{C}$ ). Moreover, cells expressing C410Y PS1 secreted even higher levels of $A \beta_{42}$ following transfection with p23 siRNA (0.41 $\mathrm{ng} / \mathrm{ml}$ in NS siRNA cells versus $0.74 \mathrm{ng} / \mathrm{ml}$ in p23 siRNA cells; $p<0.001$ ) (Fig. 5C). These data imply that p23 depletion has little influence on $\mathrm{A} \beta_{40}$ production in the presence of excess PS1 polypeptides. Furthermore, presence of FAD-linked PS1 mutation and p23 knockdown have additive effects on $A \beta_{42}$ production, consistent with independent regulation of $A \beta_{42}$ production by these two factors.

\section{Influence of p23 knockdown on the localization of APP and Mint3}

How might p23 function affect sAPP secretion? p23 is an abundant protein in cis-Golgi and ERGIC membranes, and plays an important role in biosynthetic protein transport [22]. Despite earlier evidence that suggested a cargo receptor function for p24 family members [33], endogenous p23 does not readily co-immunoprecipitate with or cross-link to APP in N2aSwe cells, formally excluding the possibility that p23 modulates APP trafficking by direct protein interaction (data not shown). We then turned our attention to potential indirect mechanism(s) that might account for the observed redistribution of APP in cells 
A
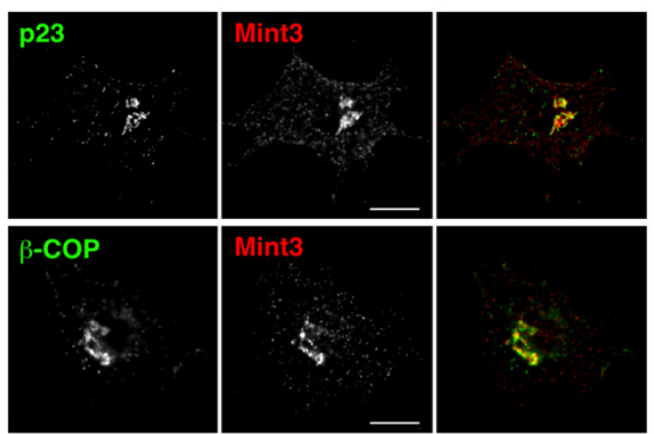

Giantin
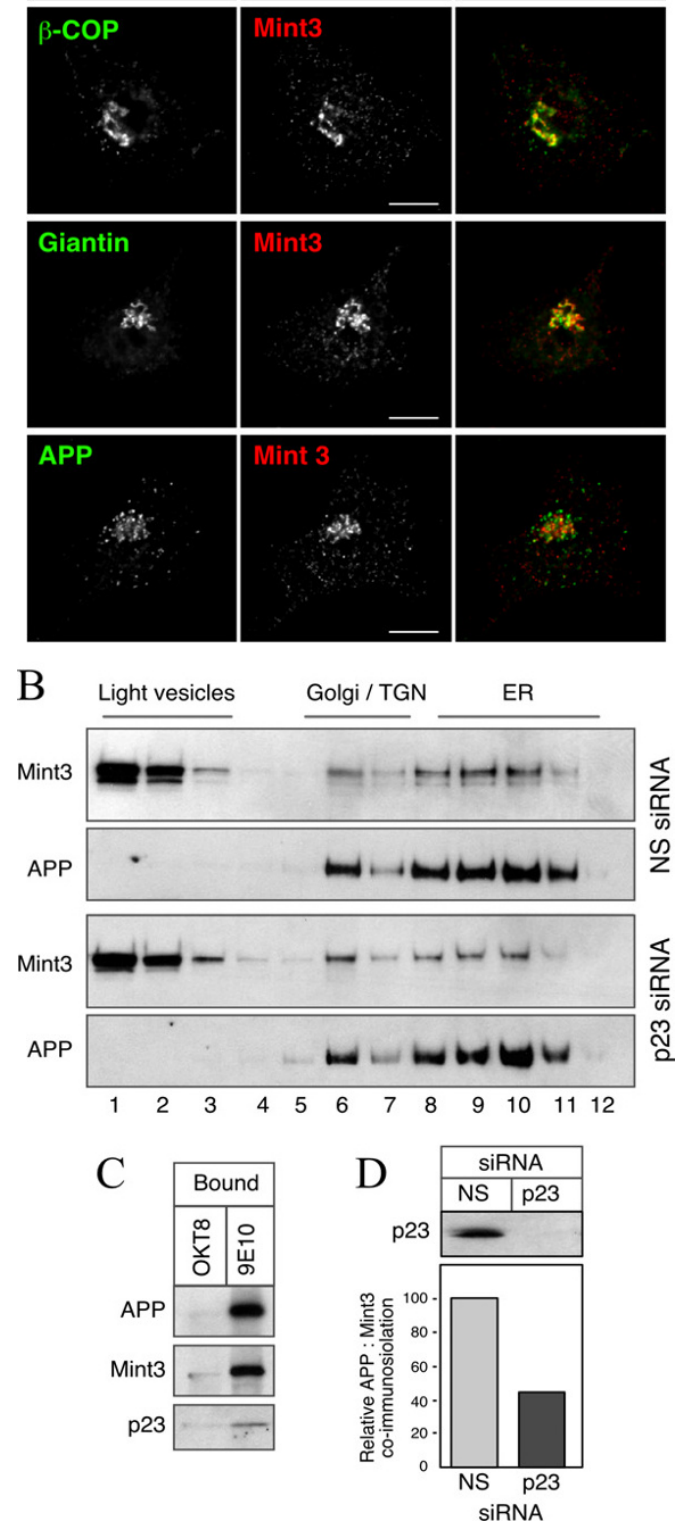

Figure 6

p23 depletion affects the co-residence of APP and Mint3. A, N2a cells transfected with control or p23 siRNA were analyzed by immunofluorescence staining with a $\mathrm{mAb}$ against APP adaptor Mint3 and polyclonal $\mathrm{p} 23, \beta-\mathrm{COP}$, giantin, or APP antibodies. Bar represents $10 \mu \mathrm{m}$. B, siRNA transfected N2aSwe cells were lysed using a ball-bearing homogenizer and fractionated by velocity sedimentation. Equal volume aliquots of fractions were analyzed by immunoblotting using antibodies against Mint3 and APP. C, Aliquots of fractions 6-12 were pooled and incubated with magnetic beads coated with mAb OKT8 (negative control) or mAb 9EI0 (recognizes C-term myc tag in APP). Bound membranes and vesicles were solubilized in Laemmli buffer and analyzed by SDS-PAGE and Western blotting. D, Immunoisolation was performed using N2aSwe cells transfected with control or P23 siRNA and relative signal intensity of co-immunoisolated Mint3 relative to APP was quantified and graphically represented. 


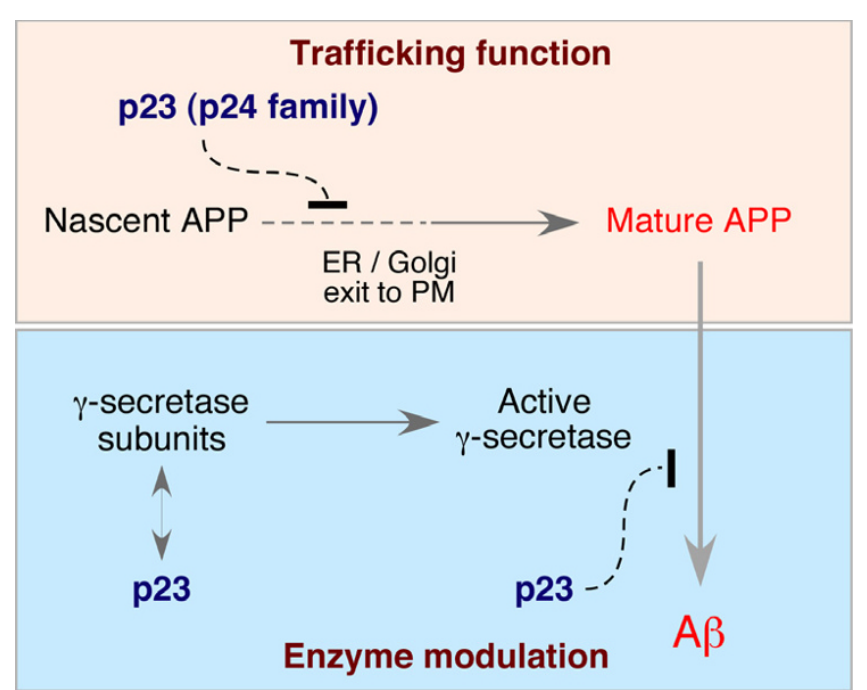

\section{Figure 7}

Model depicting the dual role of p23 in APP trafficking and processing. Our results suggest that $p 23$ has dual roles in the negative regulation of APP metabolism. First, the function of p23/p24 family proteins in early secretory trafficking of proteins at the ER-Golgi boundary influences APP biogenesis in a manner that stabilizes nascent APP, as well as enhances APP maturation and steady-state accumulation at the cell surface. Second, p23 can modulate A $\beta$ production by influencing the proteolysis of APP CTF by modulation of $\gamma$ secretase. Cells transfected with p23 siRNA secrete increased levels of $A \beta$. Moreover, absence of $p 23$ expression also results in increased $A \beta$ generated by proteolysis of recombinant APP CTF substrate in cell free assays, providing strong support for the notion that this latter function occurs independent of vesicular trafficking.

transfected with p23 siRNA. Cytosolic adaptors such as members of Munc18-interacting protein (Mint) [also referred to as X11], Fe65, Dab, and JIP family of proteins regulate $A \beta$ production by influencing APP trafficking and

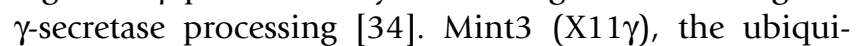
tously expressed Mint family member, is particularly interesting because it binds to ARF1, localizes to the Golgi, and can function as coat proteins to regulate APP trafficking [35]. Therefore, we asked whether p23 might influence APP trafficking by affecting Mint 3 function. First, we visualized the distribution endogenous Mint 3 and APP in N2a cells by immunofluorescence labeling. Consistent with previous descriptions, Mint 3 and APP were concentrated in a juxtanuclear location, and showed considerable overlap with COPI coatomer subunit $\beta$-COP and the Golgi marker giantin (Fig. 6A). Furthermore, when N2a cells were disrupted without the use of detergents using a ball-bearing homogenizer and fractionated through a sucrose step gradient to separate organelles based on their density, we found co-fractionation of APP, Mint3 and p23 with membranes enriched in Golgi, TGN and ER makers
(Fig. 6B). Note that Mint3 found in fractions 1-3 represents Mint3 associated with light-density vesicles, cytosolic Mint3, and Mint3 that had detached from Golgi membranes during cell lysis. The relative distribution of APP and Mint3 in sucrose density gradients was not markedly altered by p23 depletion. To obtain direct evidence for co-residence of APP, Mint3 and p23, we carried out antibody-mediated immunoisolation of APP containing vesicles and membrane organelles using magnetic beads coated with mAb 9E10 (which reacts with the C-terminal c-myc epitope tag of APPswe). Subsequent Western blot analysis revealed the presence of endogenous Mint 3 and p23, supporting the notion that APP, Mint 3 and p23 coreside in early secretory compartments (Fig. 6C). Interestingly, p23 depletion caused marked diminution in the coresidence of Mint 3 in membranes immunoisolated using magnetic beads coated with mAb 9E10 (Fig. 6D). These results show that p23 function likely influences co-residence of APP and its adaptor Mint3, providing a plausible mechanism by which p23 can affect APP trafficking and sAPP secretion independently of a direct APP-p23 interaction.

\section{Discussion}

The main finding of our work is that p23/TMP21, and likely p24 family proteins, regulate APP biosynthesis and trafficking. siRNA knockdown of p23 expression enhances biosynthetic stability of nascent APP, and leads to enhanced maturation and cell surface accumulation of APP. Moreover, our study confirms that p23 can modulate $\mathrm{A} \beta$ production as recently reported [8], and documents that p23 modulation of $A \beta_{42}$ production is independent of FAD mutant PS1-associated increase in $\gamma$-secretase cleavage of APP at the $A \beta_{42}$ site. The efficiency of $A \beta$ production is determined by multiple cellular events that control the trafficking and sequential proteolytic processing of APP. Despite remarkable progress on the characterization of APP secretases, the mechanisms that modulate cell surface transport of APP, especially during transit of nascent APP polypeptides through early secretory compartments, are not well understood. Because $A \beta$ is mainly generated in late secretory and endocytic compartments [36], positive or negative control of biosynthetic APP transport in the ER and Golgi could significantly impact on the efficiency of amyloidogenic processing. Based on previous findings and our analysis of APP metabolism in p23-depleted cells reported here, we suggest that p23 has dual roles in the regulation of APP metabolism: modulation of $\gamma$-secretase processing of APP CTF [8]; and regulation of APP biogenesis and trafficking of APP holoprotein, which can further influence $A \beta$ production (Fig. 7).

Members of the p24 family proteins cycle between cisGolgi and the ERGIC [10]. Proposed functions of p24 proteins in ER/Golgi transport include integral receptors for 
COPI and COPII coatomer components, recruitment of ARF1 to Golgi membrane, Golgi organization, de novo formation of vesicular tubular clusters, generation of ER exit sites, and the formation of tubular transport intermediates $[13,14,17,20,24,27,37]$. Deletion of yeast p24 ortholog EMP24 impaired retention of Kar2p/BiP, indicative of defects in Golgi to ER retrieval [21]. Moreover, partial defects in Golgi maturation of Gas1p (a glycosylphosphatidylinositol anchored plasma membrane protein) and secretion of invertase (a soluble protein that is secreted into the periplasmic space) in yeast p24 deletion mutants led to the suggestion that $\mathrm{p} 24$ proteins regulate cargo entry into COPII vesicles $[19,21]$. Nevertheless, secretion of carboxypeptidase $\mathrm{Y}$ and pro $\alpha$-factor were unaffected in yeast lacking all p24 proteins, arguing against an essential role in vesicular transport in the exocytic pathway [19]. Consistent with this idea, our [35S]met/cys labeling studies reveal only minor decrease in overall protein biogenesis or secretion in N2a cells upon p23 knockdown.

Based on p23 antibody-mediated inhibition of vesicular stomatitis virus $G$ protein trafficking, it was proposed that p23 plays an obligatory role in forward biosynthetic transport of transmembrane proteins in mammalian cells [22]. In contrast, loss of SEL-9 (p24 ortholog) function in C. elegans increased cell surface trafficking of mutant but not wt GLP-1 (Notch homolog). Our data demonstrate enhanced APP maturation and cell surface accumulation in cells transfected with p23 siRNA. Moreover, we find an increase in the secretion of endogenous wt APP as well as stably overexpressed FAD-associated mutant APPswe following attenuation of p24 family protein expression. These findings are consistent with improved biosynthetic transport of APP to the cell surface in the absence of p23/ p24 family function. In this regard, it is notable that PS1 deficiency also results in enhanced release of APP-containing vesicles from the ER and TGN, leading to increased maturation and cell surface accumulation of APP [39]. Considering that packaging of APP and PS1 into COPII vesicles during ER export is uncoupled [38], it is highly likely that p23 depletion affects APP FL trafficking and PS1-dependent $\gamma$-secretase activity via distinct mechanisms. In agreement, we find that expression of FADlinked mutant PS1 and depletion of p24 proteins have additive effects on $A \beta_{42}$ production. One plausible mechanistic explanation for our results is that p23 function restricts biosynthetic trafficking of APP; p23-dependent APP retention/retrieval mechanisms operating in the continuum of bidirectional transport between the ER and Golgi are compromised upon p23 knockdown, allowing enhanced transit of nascent APP from the ER/Golgi through the exocytic pathway. Thus, our study provides the important insight that p23 functions in both positive and negative regulation of transmembrane cargo trans- port in the early secretory pathway. Elucidating the precise function of p23 in controlling the fidelity of APP trafficking remains a challenge because overexpression of p23 leads to retention of exogenous and endogenous p24 proteins in the ER, causing experimental artifacts (data not shown) $[10,24]$.

Several cytosolic adaptors with phosphotyrosine-binding domains, including Mint family proteins, Fe65 family members, and Dab1 bind to the APP cytoplasmic tail at or near the YENPTY motif, and regulate APP trafficking and processing [34]. Mint proteins can directly bind to ARFs in a GTP-dependent manner, and siRNA knockdown of Mint3 resulted in diffuse localization of APP throughout the cell and concomitant decrease in juxtanuclear Golgi concentration [35]. Thus it was postulated that Mints might serve as coat proteins in regulating vesicular trafficking of APP. We find that endogenous Mint3 localizes to the Golgi apparatus and shows colocalization with p23, $\beta$-COP and giantin. Depletion of p23 markedly reduced juxtanuclear concentration of Mint3 and membrane colocalization of APP and Mint3 evidenced by immunofluorescence and magnetic immunoisolation analyses (Fig. 6 and data not shown). Together, these results raise the intriguing possibility that Mint proteins may functionally link p23 to APP cargo and influence it's trafficking. Since Mints are recruited to the Golgi membrane by interaction with ARFs [35], and recruitment of ARF1 to the Golgi is mediated by p23 [17], it is reasonable to hypothesize that p23 influence on Mint3 localization may involve ARFs. This prediction awaits direct experimental confirmation. Molecular characterization of functional interactions between $\mathrm{p} 23 / \mathrm{ARF} / \mathrm{Mint} / \mathrm{APP}$ is a focus of our future investigation. Finally, it is interesting to note that while the phosphotyrosine-binding domain of Mint proteins bind to APP cytosolic tail, the PDZ domains of Mint also bind to the C-terminus of PS1. Thus, functional interaction between p23/Mint/PS1 may be critically involved in the regulation of APP trafficking as well as $\gamma$-secretase processing.

\section{Methods \\ Plasmids, oligonucleotides, and antibodies}

Complementary oligonucleotides corresponding to three p23 target sequences separated by a 9-nucleotide noncomplementary spacer (TTCAAGAGA) were synthesized and cloned into a modified pSUPER plasmid [40]. One of the three siRNAs directed against a conserved sequence 5 'ATACCTGACCAACTCGTGA (nt 416-434 of NM_006827) present in human and mouse p23 mRNA, was identified as the most efficient by Western blotting and used for subsequent experiments. Synthetic siRNA duplexes against the above sequence were purchased from Dharmacon. A non-specific control siRNA was designed against the sequence CTGCAGAGCTCGACCACTC [41]. 
The non-specific control shRNA plasmid was generated using oligonucleotides targeted to green fluorescence protein sequence.

Polyclonal p23 antisera were generated against a synthetic peptide ISFHLPVNSRKCLREEIHKDLLVTGA, corresponding to the N-terminal luminal residues 32-57 of mouse p23. Polyclonal Ab R8666 was raised against a synthetic peptide corresponding to the C-terminal 13 amino acids of APP and affinity purified. mAb B436 reacts with the amino-terminal region of $A \beta$ and also recognizes sAPP $\alpha$. mAb B113 and $A 387$ were raised against $A \beta$ sequences and are selective for $A \beta_{40}$ and $A \beta_{42}$, respectively. Antibodies against $\gamma$-secretase components [42], and p24 family proteins p24, p25, and tp24 have been described [12]. APP C-terminal Ab 369 was provided by Drs. Sam Gandy (Farber Institute for Neurosciences, Philadelphia) and Huaxi Xu (The Burnham Institute, La Jolla). Polyclonal GRASP55 antiserum was a gift of Vivek Malhotra (University of California, San Diego). The following antibodies were purchased from commercial sources: mAb P2-1 against APP N-terminus (Biosource), mAb 5228 (Chemicon), calnexin (Stressgen), $\beta$-COP (Affinity Bioreagents, Inc.), giantin (Covance), p115 and Mint3 (BD Biosciences), OKT8 and 9E10 (ATCC).

\section{Cell culture}

Mouse N2a neuroblastoma cell lines expressing human APP695 5 SWE and human PS1 have been previously described $[29,43]$. HeLa/APP ${ }_{\text {SWEDISH }}$ cells were provided by Gang Yu (UT Southwestern, Dallas) [44]. HeLa cells were maintained in DMEM supplemented with $10 \%$ fetal bovine serum, penicillin/streptomycin, and $2 \mathrm{mM} \mathrm{L-}$ glutamine (Invitrogen). N2a cells were maintained in the medium above mixed 1:1 with OptiMEM (Invitrogen). For transient p23 knockdown, cells were transfected twice with 200 or $300 \mathrm{nM}$ p23 siRNA in $60 \mathrm{~mm}$ dishes and experiments were performed $72 \mathrm{~h}$ later. HeLa cells were stably transfected with pSUPERp23neo and the efficacy of p23 depletion in individual clones was determined by Western blot analysis.

\section{Protein analyses}

Total cell lysates for immunoblotting were prepared in IP

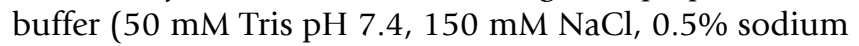
dexoycholate, $0.5 \%$ NP40, 0.25\% SDS, 5 mM EDTA, 0.25 $\mathrm{mM}$ PMSF, and supplemented with a protease inhibitor cocktail [Sigma]). Metabolic labeling using [35S]met/cys and APP immunoprecipitation were performed as described [29]. APP was immunoprecipitated from lysates and conditioned media using Ab 369 and mAb P2-1, respectively. Total protein synthesis and secretion were determined by using trichloroacetic acid precipitation combined with scintillation counting or by SDS/PAGE combined with phosphorimager detection. To measure cell surface APP, live cells were washed in cold HEPES buffer and blocked in HEPES buffer containing 0.1\% BSA for $30 \mathrm{~min}$ at $4^{\circ} \mathrm{C}$. Cells were then incubated at $10^{\circ} \mathrm{C}$ with $\mathrm{mAb}$ P2-1 for $90 \mathrm{~min}$. After washing, cells were incubated for $3 \mathrm{~h}$ at $4^{\circ} \mathrm{C}$ with $1 \mu \mathrm{Ci} / \mathrm{ml}{ }^{125}$ I-conjuated anti-mouse secondary $\mathrm{Ab}$ (Amersham Biosciences). After extensive washes, cells were lysed in IP buffer and Ab binding was quantified by $\gamma$-counting. Non-specific binding was determined by omitting primary $\mathrm{Ab}$, and specific binding was normalized to total protein concentration determined by BCA assay.

\section{$A \beta$ and sAPP $\alpha$ measurements}

Fresh medium was added to cells $24 \mathrm{~h}$ after transfection with siRNA and conditioned media were collected at $48 \mathrm{~h}$. The levels of secreted $A \beta_{40}, A \beta_{42}$, and sAPP $\alpha$ were quantified using specific sandwich ELISAs. Briefly, 96-well white ELISA plates were coated with the appropriate capture $\mathrm{mAb}$ (B113 for $\mathrm{A} \beta_{40}, \mathrm{~A} 387$ for $\mathrm{A} \beta_{42}$, and 5228 for sAPP $\alpha$ ). Following sample incubation for all three ELISAs, plates were washed and $A \beta_{40}, A \beta_{42}$ or sAPP $\alpha$ were detected with alkaline phosphatase-conjugated mAb B436 and CSPDSapphire II Luminescence Substrate (Applied Biosystems). Each sample was assayed in duplicate using appropriate dilution of the conditioned media so that the relative luminescent units were in the linear range of the standards included on each plate. For $A \beta$ quantifications synthetic $A \beta_{40}$ and $A \beta_{42}$ peptides were diluted in culture medium to generate standard curve. sAPP $\alpha$ sample relative luminescence unit values were compared to a standard curve prepared from affinity-purified sAPP $\alpha$. Briefly, conditioned medium from cells expressing human wildtype APP751 was collected and passed over an affinity column linked with a mAb that recognized $\mathrm{sAPP} \alpha$ but not sAPP $\beta$. Fractions were eluted with low $\mathrm{pH}$ and neutralized. A pooled sample containing the sAPP $\alpha$ peak was quantified by a protein assay and utilized for the sAPP $\alpha$ standard curve.

\section{In vitro $\gamma$-secretase assays}

Cell-free assays using C100FLAG substrate were performed essentially as described [30] using membranes prepared from non-specific control and p23 knockdown clones. Merck C, a highly specific biotinylated $\gamma$-secretase inhibitor [31], was used for affinity isolation of $\gamma$-secretase. The CHAPSO solubilized HeLa S3 membranes were incubated with $10 \mathrm{nM}$ of Merck $\mathrm{C}$ for $2 \mathrm{~h}$ at $37^{\circ} \mathrm{C}$ in the absence or presence of $2 \mu \mathrm{M}$ L-685,458. The samples were then incubated with streptavidin beads to capture inhibitor-bound $\gamma$-secretase complexes as previously described [31]. Bound proteins were released by incubating in SDSsample buffer and analyzed by immunoblotting. 


\section{Subcellular fractionation studies}

Confluent cells from nine $60 \mathrm{~mm}$ dishes were homogenized using ball-bearing homogenizer with a $12 \mu \mathrm{m}$ clearance and postnuclear supernatants were fractionated on sucrose density gradients essentially as described previously [42]. Twelve $1 \mathrm{ml}$ fractions were collected from the top of the gradient using a fractionator and $60 \mu \mathrm{l}$ of each fraction was analyzed by Western blotting. Immunoisolation of APP containing vesicles using magnetic beads coated with mAb 9E10 was performed essentially as described [42]. Antibody OKT8 was used as the negative control to establish the specificity of the immunoisolation procedure.

\section{Immunofluorescence microscopy}

Cells cultured on poly-lysine coated coverslips were processed for immunofluorescence analysis as previously described [42]. Primary antibodies were diluted in PBS containing 3\% BSA and $0.2 \%$ Tween-20 and added to fixed cells at room temperature for $2 \mathrm{~h}$. Images were acquired as $200 \mathrm{~nm} z$-stacks on a motorized Nikon TE2000 microscope with Cascade II:512 CCD camera (Photometrics, Tucson, AZ) using $100 \times 1.45$ NA PlanApochromat oil objective. Images were deconvolved using Huygens software (Scientific Volume Imaging BV, The Netherlands) and processed using Metamorph software (Molecular Devices Corporation, Downingtown, PA).

\section{Abbreviations}

A $\beta$, $\beta$-amyloid; APP, amyloid precursor protein; APP FL, full-length APP; ARF1, ADP ribosylation factor 1; COP, coat protein; CTF, C-terminal fragment; ER, endoplasmic reticulum; ERGIC, ER/Golgi intermediate compartment; FL, full-length; NTF, N-terminal fragment; PS, presenilin(s); shRNA, short hairpin RNA; TGN, trans-Golgi network.

\section{Authors' contributions}

KSV, PG, JWB, and YC carried out the p23 knockdown and APP metabolism studies. KSV and HC carried out the Mint interaction experiments. KSV, PG and GT carried out the immunofluorescence staining experiments. LP and Y-ML performed the in vitro $\gamma$-secretase experiments. PDN and MZK performed the ELISA. KSV, PG, JWB, FTW, Y-ML, and MZK participated in data analysis and helped to draft the manuscript. GT conceived of the study, designed experiments, coordinated data analysis and prepared the manuscript. All authors read and approved the final manuscript.

\section{Acknowledgements}

We thank Dr. Gang Yu for generously providing the HeLa/APP ${ }_{\text {SWEDISH }}$ cell line; Drs. Sam Gandy, Huaxi Xu, and Vivek Malhotra for providing antibodies; Drs. Hiroshi Yajima and Kamal Sharma for providing PSUPER-GFP plasmid; and Dr. Daria Hazuda for Merck $C \gamma$-secretase inhibitor. This work is supported by NIH grants to GT (AG02I495 and AG019070) and Y-ML (AG026660), and grants from the Alzheimer's Association (IIRG to GT; NIRG to KSV; Zenith Fellows Award to Y-ML), and American Health Assistance Foundation (GT and Y-ML).

\section{References}

I. Zheng $\mathrm{H}$, Koo EH: The amyloid precursor protein: beyond amyloid. Mol Neurodegener 2006, I:5.

2. Vassar R: BACEI: the $\beta$-secretase enzyme in Alzheimer's disease. J Mol Neurosci 2004, 23: I05-I I4.

3. Allinson TM, Parkin ET, Turner AJ, Hooper NM: ADAMs family members as amyloid precursor protein $\alpha$-secretases. J Neurosci Res 2003, 74:342-352.

4. Iwatsubo T: The $\gamma$-secretase complex: machinery for intramembrane proteolysis. Curr Opin Neurobiol 2004, I 4:379-383.

5. Vetrivel KS, Zhang YW, Xu H, Thinakaran G: Pathological and physiological functions of presenilins. Mol Neurodegener 2006, I:4.

6. Selkoe D, Kopan R: Notch and presenilin: regulated intramembrane proteolysis links development and degeneration. Annu Rev Neurosci 2003.

7. Wen C, Greenwald I: p24 proteins and quality control of LIN12 and GLP-I trafficking in Caenorhabditis elegans. I Cell Biol 1999, I45: I |65-II75.

8. Chen F, Hasegawa H, Schmitt-Ulms G, Kawarai T, Bohm C, Katayama $\mathrm{T}, \mathrm{Gu}$ Y, Sanjo N, Glista M, Rogaeva E, et al.: TMP2 I is a presenilin complex component that modulates $\gamma$-secretase but not $\varepsilon$ secretase activity. Nature 2006, 440:1208-1212.

9. Emery G, Rojo M, Gruenberg J: Coupled transport of p24 family members. J Cell Sci 2000, I I3(Pt I3):2507-25I6.

10. Blum R, Pfeiffer F, Feick P, Nastainczyk W, Kohler B, Schafer KH, Schulz I: Intracellular localization and in vivo trafficking of p24A and p23. J Cell Sci 1999, I I 2(Pt 4):537-548.

II. Barlowe C: Traffic COPs of the early secretory pathway. Traffic 2000, I:37I-377.

12. Jenne N, Frey K, Brugger B, Wieland FT: Oligomeric state and stoichiometry of p24 proteins in the early secretory pathway. J Biol Chem 2002, 277:46504-465II.

13. Sohn K, Orci L, Ravazzola M, Amherdt M, Bremser M, Lottspeich F, Fiedler K, Helms JB, Wieland FT: A major transmembrane protein of Golgi-derived COPI-coated vesicles involved in coatomer binding. J Cell Biol 1996, I35:1239-1248.

14. Fiedler K, Veit M, Stamnes MA, Rothman JE: Bimodal interaction of coatomer with the $\mathbf{2 4}$ family of putative cargo receptors. Science 1996, 273:1396-1399.

15. Dominguez M, Dejgaard K, Fullekrug J, Dahan S, Fazel A, Paccaud JP, Thomas DY, Bergeron J], Nilsson T: gp25L/emp24/p24 protein family members of the cis-Golgi network bind both COP I and II coatomer. J Cell Biol 1998, I 40:75I-765.

16. Belden WJ, Barlowe C: Distinct roles for the cytoplasmic tail sequences of Emp24p and Erv25p in transport between the endoplasmic reticulum and Golgi complex. J Biol Chem 2001, 276:43040-43048.

17. Gommel DU, Memon AR, Heiss A, Lottspeich F, Pfannstiel J, Lechner J, Reinhard C, Helms JB, Nickel W, Wieland FT: Recruitment to Golgi membranes of ADP-ribosylation factor I is mediated by the cytoplasmic domain of p23. Embo J 200I, 20:675I-6760.

18. Barr FA, Preisinger C, Kopajtich R, Korner R: Golgi matrix proteins interact with p24 cargo receptors and aid their efficient retention in the Golgi apparatus. J Cell Biol 200 I, I 55:885-89 I.

19. Springer S, Chen E, Duden R, Marzioch M, Rowley A, Hamamoto S, Merchant S, Schekman R: The p24 proteins are not essential for vesicular transport in Saccharomyces cerevisiae. Proc Natl Acad Sci USA 2000, 97:4034-4039.

20. Denzel A, Otto F, Girod A, Pepperkok R, Watson R, Rosewell I, Bergeron JJ, Solari RC, Owen MJ: The p24 family member p23 is required for early embryonic development. Curr Biol 2000, 10:55-58.

21. Schimmoller F, Singer-Kruger B, Schroder S, Kruger U, Barlowe C, Riezman $\mathrm{H}$ : The absence of Emp24p, a component of ERderived COPII-coated vesicles, causes a defect in transport of selected proteins to the Golgi. Embo J I995, I4: I329-I339.

22. Rojo M, Pepperkok R, Emery G, Kellner R, Stang E, Parton RG, Gruenberg J: Involvement of the transmembrane protein p23 
in biosynthetic protein transport. I Cell Biol 1997, 139: I I 19-1 I35.

23. Majoul I, Sohn K, Wieland FT, Pepperkok R, Pizza M, Hillemann J, Soling HD: KDEL receptor (Erd2p)-mediated retrograde transport of the cholera toxin A subunit from the Golgi involves COPI, p23, and the COOH terminus of Erd2p. J Cell Biol 1998, |43:60I-6I2.

24. Rojo M, Emery G, Marjomaki V, McDowall AW, Parton RG, Gruenberg J: The transmembrane protein $\mathrm{p} 23$ contributes to the organization of the Golgi apparatus. J Cell Sci 2000, I I3(Pt 6): $1043-1057$.

25. Emery G, Parton RG, Rojo M, Gruenberg J: The trans-membrane protein p25 forms highly specialized domains that regulate membrane composition and dynamics. J Cell Sci 2003, I I 6:482I-4832.

26. Malsam J, Satoh A, Pelletier L, Warren G: Golgin tethers define subpopulations of COPI vesicles. Science 2005, 307: 1095-1098.

27. Simpson JC, Nilsson T, Pepperkok R: Biogenesis of Tubular ERto-Golgi Transport Intermediates. Mol Biol Cell 2006, 17:723-737.

28. Marzioch M, Henthorn DC, Herrmann JM, Wilson R, Thomas DY, Bergeron JJ, Solari RC, Rowley A: Erp I p and Erp2p, partners for Emp24p and Erv25p in a yeast p24 complex. Mol Biol Cell 1999, 10:1923-1938

29. Thinakaran G, Teplow DB, Siman R, Greenberg B, Sisodia SS: Metabolism of the "Swedish" amyloid precursor protein variant in neuro2a (N2a) cells. Evidence that cleavage at the " $\beta$-secretase" site occurs in the golgi apparatus. J Biol Chem 1996, 27I:9390-9397.

30. Li YM, Lai MT, Xu M, Huang Q, DiMuzio-Mower J, Sardana MK, Shi XP, Yin KC, Shafer JA, Gardell S]: Presenilin I is linked with $\gamma$ secretase activity in the detergent solubilized state. Proc Natl Acad Sci USA 2000, 97:6138-6I43.

31. Beher D, Fricker M, Nadin A, Clarke EE, Wrigley JD, Li YM, Culvenor JG, Masters CL, Harrison T, Shearman MS: In vitro characterization of the presenilin-dependent $\gamma$-secretase complex using a novel affinity ligand. Biochemistry 2003, 42:8|33-8I42.

32. Sisodia SS, St George-Hyslop PH: $\gamma$-Secretase, Notch, Abeta and Alzheimer's disease: where do the presenilins fit in? Nat Rev Neurosci 2002, 3:28I-290.

33. Muniz M, Nuoffer C, Hauri HP, Riezman H: The Emp24 complex recruits a specific cargo molecule into endoplasmic reticulum-derived vesicles. J Cell Biol 2000, I 48:925-930.

34. King GD, Turner RS: Adaptor protein interactions: modulators of amyloid precursor protein metabolism and Alzheimer's disease risk? Exp Neurol 2004, 185:208-219.

35. Hill K, Li Y, Bennett M, McKay M, Zhu X, Shern J, Torre E, Lah JJ, Levey Al, Kahn RA: Muncl8 interacting proteins: ADP-ribosylation factor-dependent coat proteins that regulate the traffic of beta-Alzheimer's precursor protein. J Biol Chem 2003, 278:36032-36040.

36. Vetrivel KS, Thinakaran G: Amyloidogenic processing of $\beta$-amyloid precursor protein in intracellular compartments. Neurology 2006, 66:569-73.

37. Lavoie C, Paiement J, Dominguez M, Roy L, Dahan S, Gushue JN, Bergeron J]: Roles for alpha(2)p24 and COPI in endoplasmic reticulum cargo exit site formation. J Cell Biol 1999, 1 46:285-299.

38. Kim J, Hamamoto S, Ravazzola M, Orci L, Schekman R: Uncoupled packaging of amyloid precursor protein and presenilin I into coat protein complex II vesicles. J Biol Chem 2005, 280:7758-7768.

39. Cai D, Leem JY, Greenfield JP, Wang P, Kim BS, Wang R, Lopes KO, Kim SH, Zheng $H$, Greengard $P$, et al:: Presenilin-I regulates intracellular trafficking and cell surface delivery of $\beta$-amyloid precursor protein. J Biol Chem 2003, 278:3446-3454.

40. Brummelkamp TR, Bernards R, Agami R: A system for stable expression of short interfering RNAs in mammalian cells. Science 2002, 296:550-553.

4I. Ito D, Walker JR, Thompson CS, Moroz I, Lin W, Veselits ML, Hakim AM, Fienberg AA, Thinakaran G: Characterization of stanniocalcin 2, a novel target of the mammalian unfolded protein response with cytoprotective properties. Mol Cell Biol 2004, 24:9456-9469.

42. Vetrivel KS, Cheng H, Lin W, Sakurai T, Li T, Nukina N, Wong PC, $\mathrm{Xu} \mathrm{H}$, Thinakaran G: Association of $\gamma$-secretase with lipid rafts in post-Golgi and endosome membranes. J Biol Chem 2004, 279:44945-44954.

43. Sato N, Urano F, Leem JY, Kim S-H, Li M, Donoviel D, Bernstein A, Lee AS, Ron D, Veselits ML, et al:: Upregulation of BiP and CHOP by the unfolded-protein response is independent of presenilin expression. Nature Cell Biology 2000, 2:863-870.

44. Lee SF, Shah S, Li H, Yu C, Han W, Yu G: Mammalian APH-I interacts with presenilin and nicastrin and is required for intramembrane proteolysis of amyloid-beta precursor protein and Notch. J Biol Chem 2002, 277:450I3-450I9.
Publish with Bio Med Central and every scientist can read your work free of charge

"BioMed Central will be the most significant development for disseminating the results of biomedical research in our lifetime. "

Sir Paul Nurse, Cancer Research UK

Your research papers will be:

- available free of charge to the entire biomedical community

- peer reviewed and published immediately upon acceptance

- cited in PubMed and archived on PubMed Central

- yours - you keep the copyright

Submit your manuscript here:

http://www.biomedcentral.com/info/publishing_adv.asp
BioMedcentral 